\title{
Reservatório de Gás
}

\author{
Roberto Barbosa dos Santos
}

Instituto de Química, Universidade Federal da Bahia, Campus de Ondina, Salvador - BA - Brasil, CEP 40170-290 (???@ufba.br)

Objetivo

Estudar como se comportaram ao longo do tempo os depósitos de patentes e a proteção à propriedade intelectual na area de engenharia de petróleo e reservatório de gás.

\section{Aspectos tecnológicos}

O principal ponto é estudar o reservatório de gás que pode ser dividido em gás úmido, seco e gás retrógrado.

\section{Escopo}

Foram utilizadas as palavras-chave press* and reserv* and gas* e o código de classificação internacional C10 no banco de dados Espacenet, sendo encontradas 173 patentes em dezembro de 2007.

Tabela de pesquisa por palavras-chave e código de classificação internacional

\begin{tabular}{|c|c|}
\hline Palavras-chave e código & EP \\
\hline press* & $>100000$ \\
\hline reserv* & $>100000$ \\
\hline gas* $^{*}$ & $>100000$ \\
\hline oil* & $>100000$ \\
\hline recuperat* & 1647 \\
\hline fluid* & $>100000$ \\
\hline phase* & $>100000$ \\
\hline miscible & 12821 \\
\hline C10 & $>100000$ \\
\hline reserv* and C10 & 768 \\
\hline reserv* gas* and C10 & 407 \\
\hline reserv* gas* oil* and C10 & 125 \\
\hline reserv* gas* recuperat* and C10 & 1 \\
\hline reserv* oil* and C10 & 297 \\
\hline reserv* oil* press* and C10 & 196 \\
\hline reserv* fluid* and C10 & 106 \\
\hline reserv* gas* press* and C10 & 173 \\
\hline
\end{tabular}




\section{Resultados e Discussão}

1. Evolução Anual de Depósitos de Patentes

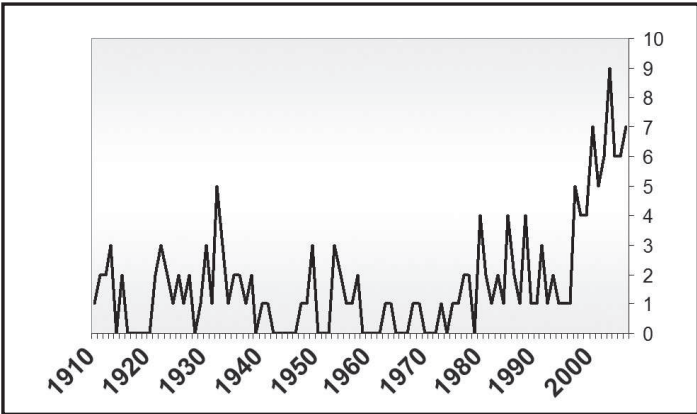

\section{Distribuição por assunto}

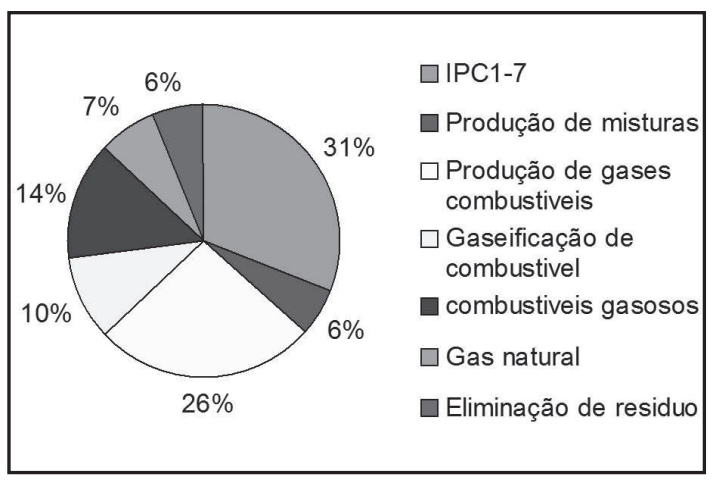

\section{Patentes por País/Organização}

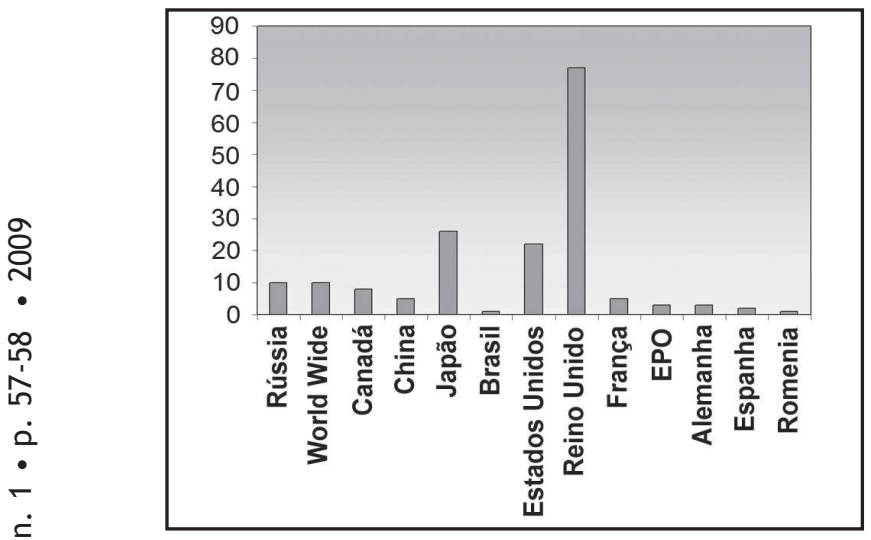

\section{Patentes por Empresa}

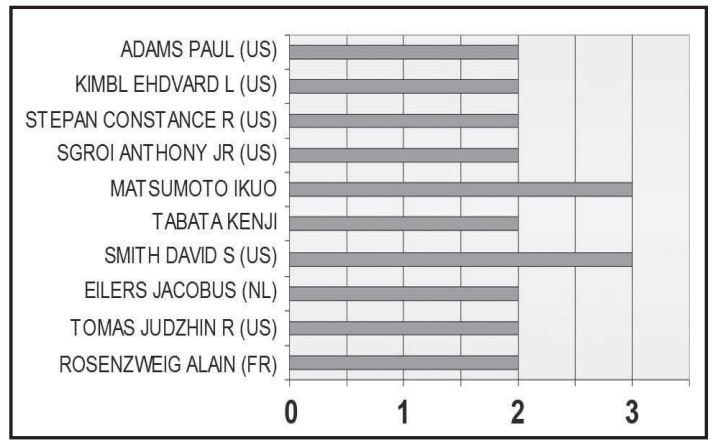

\section{Distribuição por código}

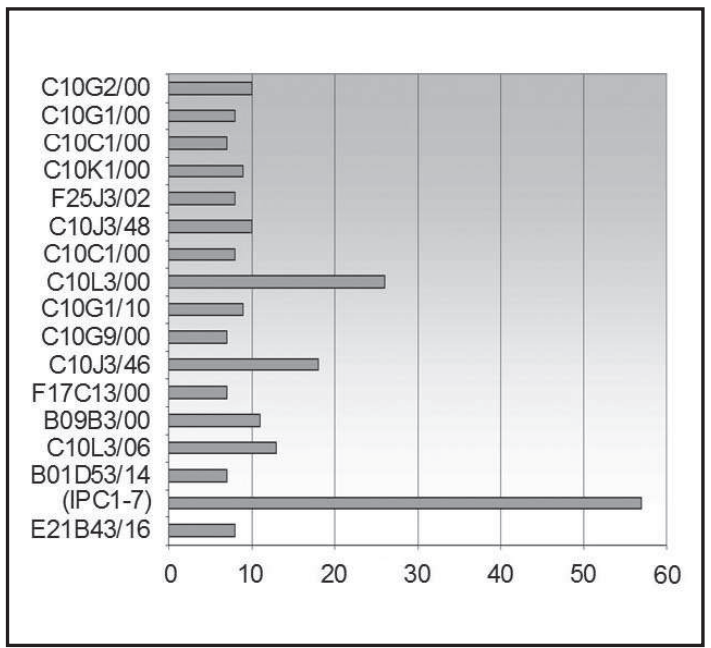

6. Patentes por Principais Inventores

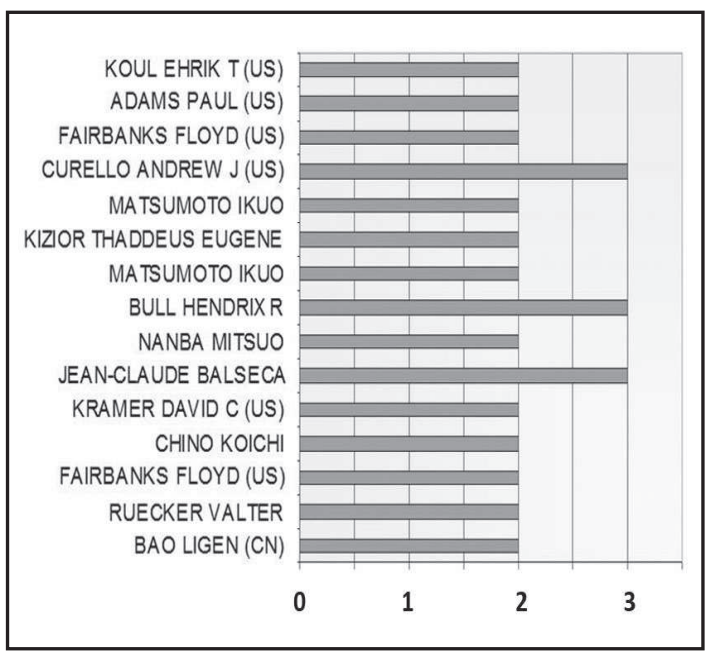

\section{Conclusões}

O país que mais depositou patentes foi a GrãBretanha , seguida do Japão e dos Estados Unidos (EUA).

Há um maior número de depósitos de patentes de inventores dos EUA.

O período de maior número de depósitos foi de 2002 a 2007, sendo ainda uma tecnologia crescente.

Roberto Barbosa dos Santos é aluno de graduação em Química da UFBA. Este trabalho foi realizado no semestre de 2007.2 durante a disciplina optativa "Marcas, Patentes e Propriedade Industrial" ministrada pela Prof ${ }^{a}$. Cristina M. Quintella. Não tinha tido contato anterior com o tema. 